\title{
Cuidado e Cuidadoras - as várias faces do trabalho do care*
}

Julian Simões**

Em suas investigações sobre violência em contextos de guerra, Butler (2006, 2010), advoga a necessidade de se pensar em uma nova ontologia corporal. Tal reivindicação exige repensar "a precariedade, a vulnerabilidade, a danabilidade, a interdependência, a exposição, a persistência corporal, o desejo, o trabalho $e$ as reivindicações a respeito da linguagem $e$ pertença social" (Butler, 2010:15, tradução minha). Dessa maneira, o corpo não é uma existência a priori ou fora de uma organização e de uma interpretação política. O corpo, para a ela, está sujeito às normas, às organizações sociais e políticas desenvolvidas historicamente com a finalidade de maximizar a precariedade para uns e minimizá-las para outros.

Faz-se necessário, então, compreender quais condições sociais de persistência e prosperidade são ou não entendidas como possíveis para legitimar certa existência corporal como vida. Para a autora, "vida não é entendida pela noção de 'a vida como tal', mas pela noção 'das condições de vidas"” (Butler, 2010:40, tradução minha). Dessa maneira, toda existência corporal necessita de condições sociais e políticas que possibilitem transformar essa existência em uma vida que valha a pena ser vivida. Nenhuma vida é a priori dotada de significados de independência, de autonomia e de autossuficiência. Todos somos vulneráveis, todos somos interdependentes e todos precisamos de cuidado. "Sinto

\footnotetext{
Recebida para publicação em 06 de março de 2015, aceita em 06 de agosto de 2015. Resenha de HiRATA, Helena e Guimarães, Nadya Araujo (Org.). Cuidado e Cuidadoras - As Várias Faces do Trabalho do Care. São Paulo, Editora Atlas S.A., 2012.

** Doutorando em Ciências Sociais, Universidade Estadual de Campinas (Unicamp), Campinas, SP, Brasil. julian_sociais@yahoo.com.br
} 
que o que está realmente em jogo aqui é repensar o humano como espaço de interdependências" (Butler \& Taylor, 2009).

Mas o que tudo isso tem a ver com o trabalho do care? Vejamos. Autoras como Tronto (1993), Gilligan (1990) e Kittay (1999), anos antes de Butler, colocaram essa problemática da interdependência e do cuidado como fundamentais para se pensar as relações sociais. Evidentemente, os contextos analíticos eram outros. No centro de suas formulações estavam as relações de cuidado mais ordinárias como as relações de cuidado com crianças, com doentes crônicos, com idosos e com pessoas com deficiência, por exemplo. Contudo, nada disso empobrece o alcance e a potência das críticas realizadas por tais autoras.

Ao tornar care uma categoria importante para se pensar relações sociais, ou, para usar a expressão de Butler, as condições sociais de persistência e prosperidade, as teóricas clássicas do tema nos fazem pensar em uma série de desdobramentos fundantes que norteiam um jogo de políticas de gestão de vidas. É ao bojo dessas complexas questões que a coletânea organizada por Hirata e Guimarães (2012) vem se juntar. Muito mais do que respostas, os treze artigos em questão nos fornecem um rico panorama de indagações, problematizações e casos concretos de impasses que traduzem a difícil realidade do trabalho de care em diferentes países. Mais, os treze artigos discutem de maneira bastante refinada a conformação de políticas públicas nacionais, a organização de fluxos migratórios, a construção de assimetrias de gênero, classe, etnia/raça e nacionalidade, bem como a constituição de gramáticas emocionais advindas do trabalho do care.

"Cuidado e Cuidadoras - As Várias Faces do Trabalho do Care" nos fornece uma rica e detalhada discussão que desloca o problema do cuidado do indivíduo para a sociedade como um todo. Os treze artigos nos interpelam sobre nossos próprios limites, sobre nossas próprias vivências, sobre nossas próprias posições sociais. O que é care? Quais as fronteiras entre trabalho do care e trabalho doméstico? A quem se destina o cuidado? Em que circunstâncias o trabalho do care é fornecido? Como garantir 
condições sociais igualitárias de acesso ao cuidado? Essas são algumas dentre outras inúmeras questões que dão o tom das discussões empreendidas pelos capítulos dessa coletânea. O que antes parecia uma discussão circunscrita a fases da vida (o cuidado de crianças ou de idosos) e a situações específicas (como as doenças crônicas ou as deficiências), ganha contornos mais amplos e versam sobre a interdependência do cuidado inerente a todas as relações sociais.

No entanto, mesmo evidenciando que todos nós, em alguma medida, necessitamos de cuidado, ainda vale destacar dois importantes pontos que perpassam toda a discussão empreendida pelo livro. $\mathrm{O}$ primeiro deles diz respeito à subvalorização e à marginalização do trabalho do care. Considerado um trabalho de menor importância, as profissionais que se dedicam ao trabalho do care sofrem com os salários baixos, a falta de garantias e direitos e com a precarização das condições de trabalho. O segundo ponto guarda uma estreita relação com o primeiro. Alguns dos artigos problematizam as questões que tangenciam uma divisão sexual do trabalho care no interior da família ou mesmo em instituições especializadas. Ao questionarem a profissionalização $e$ a remuneração desse tipo de trabalho, os artigos buscam desconstruir a associação imediata entre uma qualidade natural $e$ inata das mulheres e o cuidado.

O livro é dividido em quatro grandes partes. A primeira é intitulada de "Care, trabalho e emoções". Centra-se no debate sobre as implicações afetivas, éticas, econômicas, morais $e$ políticas que envolvem o trabalho do care. No capítulo 1, "A economia do care", Viviane Zelizer realiza uma crítica à sociologia econômica clássica e advoga por uma nova abordagem que seja capaz de compreender como também as relações afetivas, e não apenas as relações monetárias, são partes constituintes do mercado e do trabalho do care. Segundo ela, é necessário que as análises econômicas sejam capazes de compreender as relações intimas e interpessoais que constituem os processos econômicos. Somente assim é possível compreender como, no trabalho do 
care, cuidado, amor e dinheiro se imbricam e recolocam questões importantes às abordagens clássicas da sociologia econômica.

No capítulo 2 "Ética e trabalho do care", Pascale Molinier realiza uma revisão crítica sobre a categoria care fundamentando suas considerações em pesquisas realizadas com cuidadoras na França e com empregadas domésticas na Colômbia. A autora busca explicitar o caráter multidimensional do conceito, bem como suas tensões e diferentes interpretações. Assim, Molinier apresenta cinco diferenciações analíticas, ou cinco descrições como prefere ela, sobre o cuidado, são: "(1) care com gentleness, 2) care como savoir-faire discreto, (3) o care como trabalho sujo, (4) o care como trabalho inestimável, (5) o care como narrativa política" (p.30). Por fim, a autora argumenta a necessidade de politizar a categoria a fim de demonstrar como o care é um trabalho social que envolve diversos atores ocupantes de posições de poder, de decisão e de execução distintas e conflitivas.

Angelo Soares é responsável pelo último dos capítulos dessa primeira parte. Intitulado "As emoções do care", o capítulo 3 analisa o trabalho de cuidar enfatizando os aspectos emocionais que nele está envolvido. Centrando-se naquilo que ele chama de trabalho emocional - uma das dimensões do trabalho do care, segundo o autor -, Soares intenta investigar a importância de emoções como medo, raiva, alegria, tristeza, empatia, frustração, entre outras tantas, como parte constituinte do trabalho de cuidado. Chama atenção ainda para as assimetrias de poder que emergem na relação entre cuidador, família e beneficiário do cuidado.

A segunda parte do livro, também composta por três capítulos, é intitulada de "Configurações sociais do care". Nela temos uma comparação em âmbitos nacional e internacional das diferentes formas de organizar, prover e garantir o acesso ao trabalho oferecido pelos cuidadores. No capítulo 4, "Rumo a uma sociologia econômica do trabalho do care: comparando configurações em quatro países europeus", Miriam Glucksmann nos apresenta uma pesquisa realizada em França, Holanda, Reino Unido e Suécia. O intuito é comparar os modos de provisão 
(Estado, família, voluntariado e mercado), financiamento $e$ realização do trabalho do care, sublinhando as semelhanças $e$ diferenças existentes nesses quatros países. Dessa maneira, a autora se empenha em detalhar os contextos de provisão, bem como analisar os processos generificados que a função de cuidado instaura. Esses, diz Glucksmann, são processos indissociáveis que dizem muito da organização econômica, política e moral desses países.

Nadya Guimarães, Helena Hirata e Kurumi Sugita também tomam como alvo de análise explorar a diversidade de configurações socioeconômicas de provimento e trabalho de cuidado. O capítulo 5, "Cuidado e cuidadoras: o trabalho do care no Brasil, França e Japão", assenta especial ênfase na tênue fronteira existente entre trabalho profissional de cuidado e o trabalho doméstico em cada um dos três países analisados. Dessa maneira, as autoras descrevem como os contextos do mercado de trabalho, da organização familiar e das políticas de Estado se conformam em noções singulares nas figuras de auxiliaires de vi na França, homehelpes no Japão e cuidadoras no Brasil.

Encerra essa segunda parte o capítulo 6, "O care como regime estratificado: implicações de gênero e classe social", de Bila Sorj e Adriana Fontes. Nele, o contexto brasileiro é mote de análise. As autoras procuram indicar como desigualdades sociais conformam o regime de care no país. Para tal, analisam algumas provisões fornecidas pelo mercado, pelo Estado e pela família, ou seja, respectivamente: os serviços domésticos, o acesso a creches e pré-escolas e a divisão sexual do trabalho não remunerado. A partir disso, Sorj e Fontes explicitam que as dimensões de gênero $e$ de classe social se entrecruzam aumentando e reforçando as desigualdades sociais, uma vez que o regime de care reflete a inserção das mulheres no mercado de trabalho.

A terceira parte da coletânea é composta por quatro artigos e intitulada "Care, políticas públicas e profissionalização". Aqui é realizada uma importante discussão sobre os processos sociais $e$ políticos que envolvem a profissionalização dos trabalhadores do care e o lugar que eles ocupam em políticas públicas estatais. A 
discussão é iniciada com o capítulo 7, "Cuidadoras domiciliares: que tipo de profissionalização?". Thierry Ribault empreende uma importante discussão sobre a profissionalização dos assalariados que oferecem serviços de cuidado em domicílio na França. A hipótese do autor é que as relações de serviço oferecidas pelos cuidadores se inscrevem em registros de profissionalidades variados. Tal fato explica os impasses existentes atualmente na profissionalização do auxilio em domicílio naquele país, uma vez que esse processo de profissionalização segue uma lógica de organização - o que ele chama de convenções da profissionalidade - incapaz de reconhecer a diversidade de maneiras pelas quais esses serviços podem ser oferecidos $e$ profissionalizados.

No capítulo 8, "Como tornar visível o trabalho das cuidadoras domiciliares? $\mathrm{O}$ caso das políticas em relação à dependência na França", Loïc Trabut e Florence Weber objetivam analisar um conjunto de processos históricos específicos advindos das relações entre trabalho do cuidador e sua remuneração. Para os autores, tais relações implicam em mudanças tecnológicas significativas, em transformações políticas, bem como a emergência de novas normas sociais relacionadas às políticas públicas de assistência social francesa. Dessa maneira, a investigação se detém especificamente na análise do benefício para pessoas idosas e deficientes concedido pelo sistema público de Previdência Social da França - também conhecido como "Quinto Risco" ou "Risco dependência". Concluem, então, que a política francesa de assistência para pessoas em situação de dependência é ambivalente, uma vez que enfatiza a necessidade de profissionalizar os serviços de cuidado ao mesmo tempo em que se recusa a remunerar adequadamente esses profissionais.

No capítulo 9, "Cuidados de longa duração para a população idosa: um novo risco social a ser assumido?", Ana Amélia Camarano discute como o envelhecimento atrelado ao aumento de doenças crônicas entre os idosos, se desdobra no aumento da demanda por cuidados. De tal modo, esse aumento de demanda desafia os sistemas de seguridade social de grande 
parte dos países, uma vez que esses cuidados de longa duração não devem ser pensados como uma responsabilidade exclusivamente familiar. Com a finalidade de fortalecer seu argumento, Camarano analisa a realidade brasileira evidenciando como essa responsabilidade é delegada à família. Assim sendo, advoga que a provisão de cuidados aos idosos frágeis se configure num entrelaçamento entre Estado, familia e mercado privado.

Finalizando essa parte, Isabel Georges e Yumi Garcia dos Santos discutem o trabalho do care realizado pelas agentes comunitárias de saúde e pelas agentes de proteção social. O capítulo 10, "Care e políticas públicas: o caso das "agentes comunitárias de saúde' e das 'agentes de proteção social'", portanto, prossegue analisando a realidade brasileira. Contudo, centra sua atenção num campo de tensões $e$ ambiguidades relativas à gestão das políticas públicas de saúde ligadas ao Programa de Saúde da Família e ao Programa Ação Familia. Para elas, esses programas não são exitosos no combate às desigualdades sociais, uma vez que recolocam em outros termos, essas mesmas desigualdades que tentam combater. Além do mais, as autoras analisam o lugar das mulheres como agentes reprodutoras, reparadoras e transformadoras dessas desigualdades, bem como os riscos contra a integridade física $e$ moral assumido por essas mulheres no fazer político às margens do Estado.

A quarta e última parte é composta por três artigos $e$ intitulada de "Care e migrações internacionais". O foco está em pensar como os fluxos migratórios são elementos importantes $e$ paradoxais para consolidar, mas também tensionar, um crescente mercado do trabalho do care. O capítulo 11, "Nos bastidores do livre mercado local: babás e mães de aluguel", de Arlie Hochschild, é uma contundente análise realizada sobre trabalhadoras migrantes. A autora busca evidenciar a gramática emocional que emerge por meio do trabalho afetivo de cuidar de pessoas. Para a migrante trabalhadora torna-se inescapável as dilacerantes rupturas consigo mesmo e com a relação familiar abdicada. Assim, vemos surgir casos como o de Vicky, uma babá 
filipina, que migra para os Estados Unidos para trabalhar junto a uma família rica em Beverly Hills. "O que é paradoxal", afirma Hochschild, "é que Vicky também contribui, inadvertidamente, para elevar uma desigualdade emocional global. Ela priva seus próprios cinco filhos do cuidado materno diário e acrescenta uma segunda camada de cuidado amoroso a uma criança norteamericana" (p.188).

Tão contundente quanto Hochschild, o capítulo 12, "O trabalho de care das acompanhantes. Imigrantes filipinas em Tóquio", de Rhacel Salazar Parreñas, mergulha nos rituais cotidianos realizados pelas acompanhantes filipinas na indústria do entretenimento adulto noturno. Através de uma descrição realizada por meio de uma pesquisa etnográfica, a autora investe nas formulações que ampliam a noção convencional de care, visto que infere que o trabalho sexual realizado por essas mulheres migrantes é um serviço de cuidado assim como os demais serviços de cuidado oferecidos para idosos, por exemplo. Parrenãs não se furta também de colocar o paradoxo existente nessa forma de trabalho, pois ao mesmo tempo em que abre espaços para a transformação, reifica relações desiguais de gênero $e$ nacionalidade entre mulheres filipinas e homens japoneses.

Encerrando as discussões empreendidas pelo livro, no capítulo 13, "Imigrantes, Estado e família: o cuidado do idoso e suas vicissitudes", Guita Debert realiza uma cuidadosa e provocante discussão que entrelaça políticas públicas estatais, família e fluxos migratórios. Em um primeiro momento, a autora discute as práticas de cuidado realizadas em alguns países europeus. Dessa maneira, constata que o déficit de políticas públicas relativas ao idoso é facilmente driblado pela contratação de mulheres migrantes - quase sempre ilegais. Paradoxalmente, essas mulheres são invisíveis para o Estado, ao mesmo tempo em que recebem, via família dos idosos, recursos advindos desse mesmo Estado que a desconhece. Eis o caso da maioria das badantis italianas. Num segundo momento do texto, estabelece um diálogo crítico com a literatura gerontológica que afirma ser um desejo universal dos idosos receber cuidado advindo do 
interior da família. Através de cuidadosa pesquisa etnográfica, Debert ressalta a importância de conceber a experiência do envelhecimento como heterogênea. Por fim, a autora aponta para a necessidade de se pensar práticas inovadoras capazes de transformar o envelhecimento em uma experiência que nãos seja um fardo nem para família, nem para o Estado.

Dessa forma, a publicação de "Cuidado e Cuidadoras - As Várias Faces do Trabalho do Care", como bem colocam Hirata e Guimarães preenche uma lacuna no que diz respeito à questão do cuidado e do trabalho dos cuidadores no mundo acadêmico e no mercado editorial brasileiro. Diria mais. A coletânea organizada por Hirata e Guimarães nos faz pensar em engajamentos morais $e$ emocionais que estão presentes em políticas de Estado, em fluxos migratórios e em relações de trabalho. Para retomar o início desse texto, o livro ajuda, ainda, como disse Butler e Taylor (2009) a "repensar o humano como espaço de interdependências" (grifos meus).

\section{Referências bibliográficas}

BUTLER, Judith. Vida Precaria. El poder Del duelo y La violencia. Buenos Aires, Paidós, 2006 [2004].

. Marcos de guerra. Las vidas lloradas. Buenos Aires, Paidós, 2010 [2009].

BUTLER, Judith \& TAYLOR, Sunaura. Judith Butler with Sunaura Taylor: Interdependence. In.: TAYLOR, Astra. Examined Life: Excursions with Contemporary thinkers. New York, The New Press, 2009, pp.185-213.

Gilligan, Carol. Uma voz diferente. Rio de Janeiro, Rosa dos Tempos, 1990 [1982].

KITTAY, Eva F. Love's Labor: Essay on Women, Equality and Dependency. New York, Routledge, 1999.

TRONTO, Joan. Moral boundaries: a political argument for an ethic of care. New York, Routledge, 1993. 